\title{
Congenital dyserythropoietic anemia type III
}

INSERM

\section{Source}

INSERM. (1999). Orphanet: an online rare disease and orphan drug data base. Congenital dyserythropoietic anemia type III. ORPHA:98870

Congenital dyserythropoietic anemia type III (CDA III) is a rare form of CDA (see this term) characterized by dyserythropoiesis, with big multinucleated erythroblasts in the bone marrow, and manifesting with mild to moderate anemia. 